\title{
Towards a common architecture paradigm for the global application of information technology
}

\author{
Hans Lehmann
}

Department of Management Science and Information Systems

University of Auckland, New Zealand

Private Bag 92019

Auckland, New Zealand

Tel $6493737599 \times 8659$

Fax 6493737430

Emailh.lehmann@auckland.ac.nz

\begin{abstract}
:
The serious difficulties facing the developer of international systems (ie supporting business functions in different countries) are widely acknowledged. Despite their often pivotal importance, however, scholarly research in this field has been sparse and global information technology applications are still largely unstudied and under-explored. This investigative paper attempts to establish whether there is some commonality to the structure and nature (ie. the 'architecture') of international systems. The investigative method selected is based on a grounded theory approach, attempting to establish a set of preliminary theoretical 'concepts' and 'categories'. Three case vignettes from the author's own experience are used to establish a conceptual base.

A two-dimensional topology emerged as a candidate for an architecture paradigm. The implications of this concept are discussed in terms of its impact on the development of international information systems. A correlation between the shape of the systems topology and the underlying global business strategy was found. Directions for further research are outlined.
\end{abstract}

\section{Keywords}

International information systems, architecture of information systems, qualitative research in information systems, theory building methodology, systems architecture modelling 


\section{INTRODUCTION}

Information systems technology is often critical to the international operations of the globally oriented firm, either as the key to its expansion, or even as the main profit driver. Despite their obvious importance, however, transnational information systems technology is still "largely unreported [and] unstudied" (Cash, McFarlan and McKenney, 1992) and "..generally ignored." (King and Sethi, 1993). While scholarly research into this field is sparse, there is an increasing amount of anecdotal evidence and technical reports indicating a strengthening interest by practitioners in this field.

\subsection{Definition of 'International Information Systems'}

The literature does not clearly identify a generally accepted term for the application of information systems technology across borders. Often "global" is used (eg by Ives and Jarvenpaa, 1991), but "transnational" is also in general use (eg by King and Sethi, 1993) for such systems. The first inevitably invites associations of vast enterprises covering the planet, whereas "transnational" is open to possible confusion with the precise use of the term coined by Bartlett and Goshal (1989) for describing one specific style of a firm's operation in more than one country. In this paper, therefore, the term "international" ${ }^{1}$ is used.

Another definition is needed to distinguish international system from other distributed systems. Information systems which support different business activities, eg in multi-divisional companies, are different by definition, whether theses divisions are in a single or multiple locations, national or international. Similarly, systems supporting different business functions (such as Sales, Manufacturing, etc) are different for each function, again independent of their location, be they all in one place or spread over several continents ${ }^{2}$.

'International Information Systems' are defined as distributed information systems which support similar business activities in highly diverse environments commonly found across country boundaries.

A classification of firm's international operations along the dimensions of 'business focus' and 'environmental diversity' (of their operating locations) may help to sharpen the definition. 'Business Focus' is high in operators who concentrate on a single business activity. Examples are car rental firms, international banks and international franchises. Low business focus is present in diversified conglomerates with many activities. Examples are the large Japanese and American multinationals. Low Environmental Diversity ${ }^{3}$ would typically be encountered within one country and high diversity across different countries with divergent business cultures.

This paper deals thus with the information systems for the 'International Operator', ie where a single business activity is carried out in different countries ${ }^{4}$.

1 This too has been used by Bartlett and Goshal, but in a more general sense.

2 However, where these disparate sites have a common information need, such as common management and financial information across divisions and/or functional sites, the (sub)systems serving this need are 'international' in the sense of our definition.

3 This includes differences such as business practices, cultural influences, political regimes;

4 However, this is not a limiting restriction as each of the divisions or functional entities of an international conglomerate is often an 'international' operator itself. 


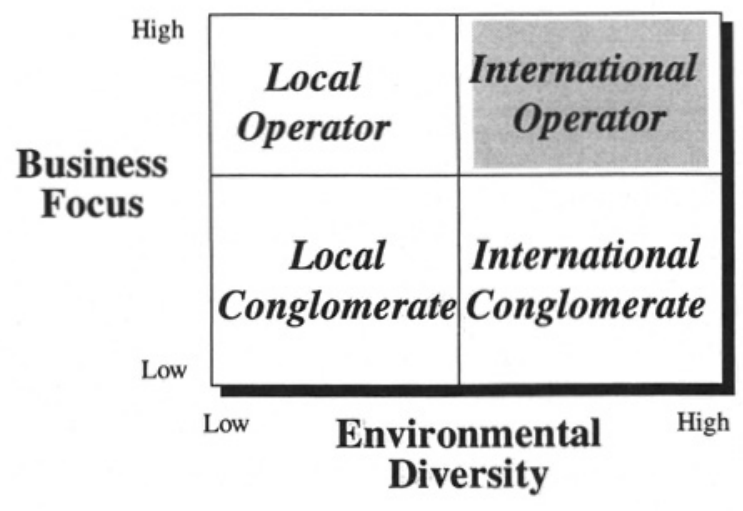

Figure 1. Classification of firms by business focus and diversity of their operating environment

\subsection{Structure of the Paper}

The paper is structured as follows:

- First, the literature on international systems is reviewed;

- Second, research approaches for international systems are discussed and a method is suggested to develop a base concept for initial research;

- Next, three case vignettes are used to test the base concept;

- Finally, the resultant concept is critically evaluated and directions for further research are outlined.

\section{INTERNATIONAL INFORMATION SYSTEMS IN THE LITERATURE}

Past research into international information systems is sporadic and spread over a wide array of topics. In the 1970s a main focus was on the issues of trans-border data flows (summarised by Hamelink ,1984).

Since 1985 the issues have widened to also include planning, decision support and management contingencies.(summarised by King and Sethi, $1993 \mathrm{~b}$ ). A number of attempts have been made to set out a taxonomy of issues and to classify the research areas related to international information systems: Sethi and Olson (1993) and King and Sethi (1993 b) both attempted to establish a framework for international information systems, the former addressing the firm-internal environment and the latter also encompassing the external influences on the international firm. Other work concentrated on the 'drivers', ie the factors exerting pressure on firms to operate information technology globally. Applegate and Mason (1991) and Ehrlich (1989) link the business reasons for global expansion to the nature of information technology employed. Ives and Jarvenpaa (1991) defined a set of ten 'business drivers for global information technology'. Whereas most of those are operations oriented, Butler Cox (1991) and Neo (1991) also found a significant marketing dimension as a factor in shaping global information technology. 


\subsection{Difficulties with international information systems}

Whilst scholarly research concentrated on the wider issues, within the practitioner community there seems to be a widespread consensus emerging that international systems are a not only a major element of any global strategy but also a major, potential, stumbling block for global operators. The fact that only $8 \%$ of a large sample of European multinational companies have managed to implement international systems satisfactorily (KPMG, 1993) indicates the difficulties encountered. The issues are technology related problems and those of cultural diversity. A selection of - sometimes anecdotal - evidence for this is presented below.

\section{Technology related difficulties}

In a comprehensive review Huff (1991) identified critical, constraining issues as extending practically across all functional areas of the traditional systems management and development framework:

- Failure to link information technology and business strategy (Popper, 1990, LaPlante, 1991)

- Unsuitable development methods (Passino, 1990, Popper, 1990 and Laplante, 1991);

- Technical complexities and adverse legal aspects of telecommunications (LaPlante 1991 and Kobielus, 1992);

- Hardware incompatibility and failure to establish interconnectivity (LaPlante, 1991);

- Lack of and/or incompatible technology standards (Palframan,1991);

\section{Issues of cultural diversity}

The assumption that international business is just a replication of domestic business, has been refuted for general business a long time ago (eg. Doz, 1980, Buss, 1982). Several researchers have more recently established that this assumption is also wrong for information systems.

Robey and Rodriguez-Diaz (1989) found that cultural differences proved a significant impediment to the implementation of an accounting system in one of two Latin American countries. Heitzman (1990), in a study on the acceptance and the influence of information technology in South East Asia sees the regionalisation/localisation of system development and implementation efforts as a way to ameliorate the difficulties experienced across cultural and developmental divides.

These findings were confirmed in a wide ranging analysis of multinational issues in information technology in less developed countries (Saraswat and Gorgone, 1991).

Whereas these studies concentrate mainly on the effect of different development levels there are also differences in value systems, business philosophies (especially ethics) and general living habits between different locations of an international system. Goodman and Green, (1992) demonstrate this with an analysis of the information technology environment in the Middle East. A recent comparative study of management styles, perceptions and expectations across western Europe (Barsoux, 1992) revealed a variety of differences in the role of management, which can be of major significance for systems design and implementation.

In conclusion, the past research on international information systems is wide spread and not always sharply focussed. There is as yet no coherent theory of the specific nature of international information systems (or even consensus on whether such specificity indeed exists) which could be of sufficient practical value to address the difficulties experienced with international information systems. However, some research has been done about the architecture of international information systems - an area which may have a bearing on the difficulties experienced.

The literature is not conclusive on the link between the 'goodness' of systems architecture and the effectiveness of systems development approaches. However, the value of an 'infrastructure' (Weill, 1992) of sufficient 'reach and range' (Keen, 1991) is accepted as essential for providing the flexibility to deal with 
future systems demands. Earl (1989) suggests that a typical information technology architecture (which he also defines as the prerequisite for such an infrastructure in Weill's sense) contains 'blueprints' for the development of application systems. It is thus safe to assume that establishing an appropriately specific architecture for international systems would have a beneficial impact on their development.

Systems architecture is defined in many ways. For the purpose of this exploration a working definition of architecture is borrowed from Earl (1989): "[Information technology architecture is] the technology framework which guides the organisation in satisfying business and management information systems needs". This also encompasses functional applications in the sense of Weill's (1992) "enabling foundation [for the application of the technology]".

\subsection{The structure of international systems in the literature}

A number of researchers have found that the architecture of international systems seems directly influenced by the strategy and structure of the international firms which use them (King and Sethi, 1993; Sankar, Apte and Palvia, 1993; Kosynski and Karimi, 1993; Butler Cox, 1991; Ives and Jarvenpaa, 1991). Therefore the strategic management of global firms is briefly discussed first, before systems architectures are investigated.

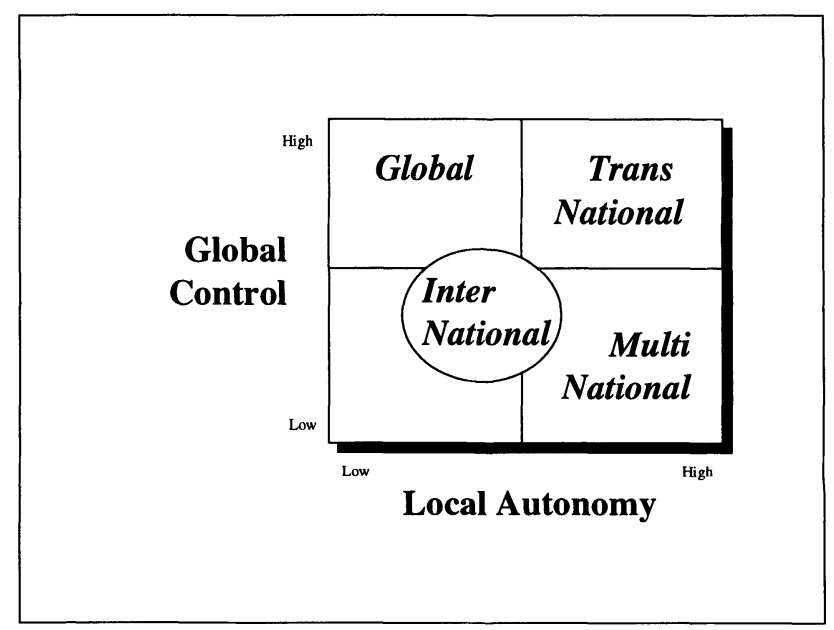

Figure 2. Global business strategies

The major factors shaping an international firm's operations and management structure seem to be the level and intensity of global control versus local autonomy. The model developed by Bartlett and Goshal (1989), illustrated in Figure 2, seem best to integrate business strategy with the organisational forces acting upon the international firm:

- The 'global' business strategy shows a high degree of global control at the expense of local autonomy;

- Juxtaposed to this is the 'multinational' strategy with loose global and high local control;

- 'Transnational' organisations balance tight global control in certain aspects with a policy of vigorously fostering local autonomy, particularly for the diffusion of innovation. These firms "think global and act 
local" (Bartlett and Goshal, 1989). This strategy is considered optimal for many multinational corporations;

- Defined as an interim stage, the 'international' firm strikes a balance between global and local control, often with neither control modus dominant.

In the context of international systems, there is very little evidence of research towards an architecture model specifically derived for this class of system. There is evidence of the importance of having an 'architecture strategy' for global systems (IS Analyzer, 1991). The architecture of the 'global village' (Targowski, 1990), with its backbone of electronic highways connected to information utilities could provide a starting point for an architecture model. The need for an 'infrastructure' to allow connection between individual parts in the form of a central network (IS Analyzer, 1991) - points in the same direction. Bingham and Pezzini, (1990), researching logistics systems, set out the requirement for a 'common carrier information system' into which generic, packaged application systems can interface.

Butler Cox (1991) classify information systems structures according to systems management style. In their model (in which 'systems' is defined as technology and applications) there is a direct, one-to-one relationship between the global business strategies and these systems architectures. They distinguish between

- 'Centralised' systems, with local terminals connected to a centrally developed and operated system;

- 'Replicated', ie. copies of one (centrally developed and maintained) system are operated in all local sites;

- 'Autonomous', ie. locally developed and operated systems which have little in common with each other; and finally

- 'Integrated' systems, locally operated and assembled from compatible components developed at different local and /or central sites.

Kosynski and Karimi (1993) develop a very similar relationship between information systems structure and business structure, which (in the same sequence as above) they name 'centralisation', 'interorganisational' (to emphasise the link-up between local databases and processes), 'decentralisation' and 'integrated architecture'. The key elements in their architecture model are network and data management strategy.

Sankar, Apte and Palvia (1993) define global information architecture mainly in terms of the configurations of two architectural elements, one mainly hardware and the other mainly operating software of the 'middleware' type. Their architecture model thus explicitly excludes application systems. These elements can then be structured in three configurations:

- Integrated (elements are physically separate, but logically connected);

- Centralised (together and connected);

- Decentralised (separate and disconnected).

The three configurations of the two elements result in nine possible architectures of which four, however, are either not feasible or inappropriate. Three are the 'pure' versions (with both elements in the same configuration) and two are mixed. 


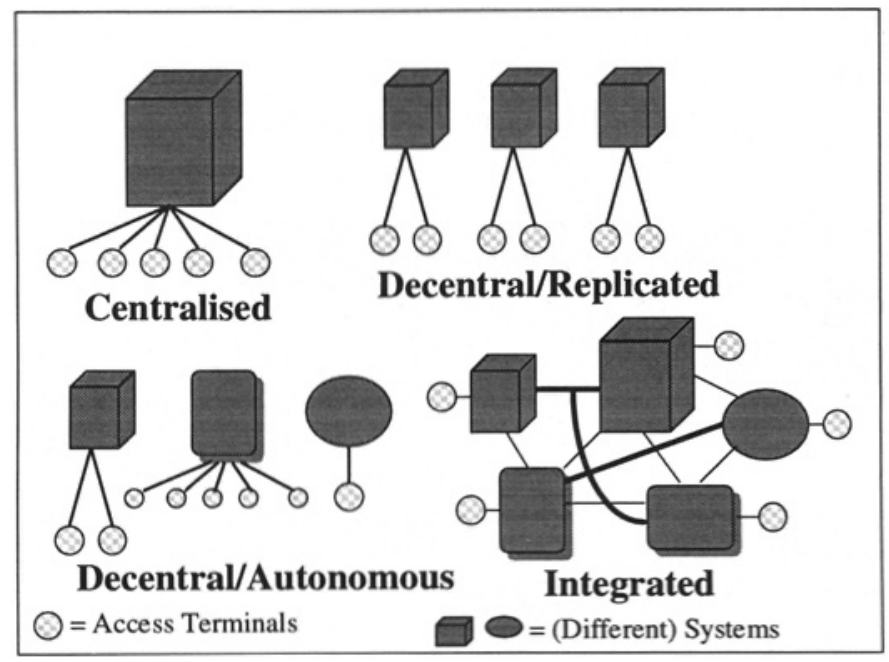

Figure 3. Architectures and configurations of international information systems

Figure 3 summarises the architectures and systems configuration structures discussed above. If the replicated/decentralised structure is disregarded as a physically distributed incarnation of the centralised architecture, there are thus three generic architectures outlined, namely centralised,

autonomous/decentralised and integrated.

Whilst these studies are a first approach towards increasing our understanding of international information systems, they are well short of providing a research agenda which can address the issues in a methodical way.

\section{SELECTION OF A RESEARCH METHODOLOGY FOR INTERNATIONAL INFORMATION SYSTEMS}

Given the rudimentary state of the body of research into international information systems, it seems that theory building methods are an appropriate choice of methodology. These tend to be qualitative and inductive in nature.

Such methods are now well accepted for organisational research and are also becoming more widespread in information systems research (Turner, 1983, Benbasat et al, 1987, Galliers et al, 1987, Yin, 1989, Lee, 1989, Orlikowski et al, 1991, Zinatelli et al 1994). In particular, Eisenhardt (1989) describes the process of building theory, especially the central inductive process and the role of literature, ie the incorporation of previous research. Glaser and Strauss (1967) had set out - for sociological research initially - how to develop theory that is actually grounded in data and how this empirical connection permits the development of a testable, relevant and valid theory. Orlikowski $(1993,1995)$ in particular has pioneered the use of grounded theory in Information System Research.

There is no clear guidance in the Information System Research literature for what the nature of the 'starting point' in a theory building exercise should be. Whilst Eisenhardt (1989) acknowiedges the importance of a 'well focused research question' she also puts a strong emphasis on '[beginning the research] as close as possible to the ideal of no theory under consideration and no hypotheses to 
test'. Similarly, Galliers and Land (1987) show a theory development progression which begins straight off with 'case study/action research', from which is developed a research question which in turn aids theory development.

Glaser and Strauss (1967), on the other hand, actively encourage the use of what they call 'anecdotal comparisons':

"Through his own experiences, general knowledge, or reading, and the stories of others, the sociologist can gain data .,.that offer useful comparison. This kind of data can be trusted if it has been 'lived'. Anecdotal comparisons are especially useful in starting research and developing core categories"

Their theory development progression therefore starts with such a conceptual construct with which to start the research. During the research, the empirical facts unearthed then harden these into 'categories and their properties'. A linked set of such categories then forms the first 'substantive' theory, which in further research may be widened into a 'formal' theory.

Glaser and Strauss' progression of theory development seems to tie in closest with the prevailing thought on knowledge acquisition within the philosophy of science. Although there does not seem to a common terminology, the underlying ideas seem related among researchers. In a classic work, Wolf (1922) sees 'working ideas', formulated as 'principles' or 'postulates' (Glaser and Strauss' 'concepts') turning into hypotheses by the application of a method. Kuhn (1970), often referred to as the doyen in this field, defines a 'paradigm' as the igniting force for the forming of new theory. This is a set of propositions

"sufficiently unprecedented [and] ..simultaneously, sufficiently openended to leave all sorts of problems...to resolve"

Merton (1968) refers to 'seminal ideas', often developed with the aid of a 'serendipity factor' as the starting point of a process to formulate what he terms 'theories of the middle range'. These are at the bottom of a hierarchy of knowledge and are roughly congruent with Glaser and Strauss' 'substantive' theories. Wartofsky (1968) sees such constructs as the end product of a process of stepwise abstraction, beginning with abstractions of (sensory) perception and ending with 'conceptual abstraction, ie the codification of such singular abstractions into 'concepts'. These are then the first building blocks for

\section{"..further reflection on the concepts themselves which marks.. the beginnings of theoretical scientific inquiry." "}

Ziman (1984) refers to this class of seminiferous thought as 'patterns of fact' in need of 'simplifying generalisation' and 'definite association'. Donovan et al (1988) refer to the need for 'guiding assumptions' as the prerequisite for any research undertaking. Gergen (1978) and Pfeffer (1982) argue even further that the very selection of research objects is conditioned by pre-established concepts and values and that the notion of 'pure' theory is a mirage. Selye (1964) also subscribes to a more deductive view: new 'idea-units' are classified into existing categories and new research questions are developed from reviewing where current research has left gaps - ie, the process of 'normal science' in Kuhn's (1970) terms. However, Selye's model also leaves space for the 'intuitive flash (hunch)', the inductive element, without which no really new ground can be explored. 
In conclusion, it seems therefore appropriate to adopt the Glaser and Strauss theory building model, as the basis for grounded theory research using their method of comparative analysis.

The starting point of such a course of investigation is thus the establishment of a suitable concept as the 'seed' for the theory. Having selected the architecture of international information systems as an appropriate topic of research to address the difficulties experienced by practitioners, such a concept should have an architecture model as its subject.

\subsection{An architecture model for international information system}

International information systems are defined as supporting a common function across a number of local sites. The first and most fundamental common sense deduction from this is the obvious requirement that such systems would have parts that are common to all sites and other parts which are specific to individual localities.

Not surprisingly then, the need for variation in international systems to accommodate differing local circumstances has been established early on by Buss (1982), when he found that using 'common' systems across different countries can be fraught with difficulty. In the same year Keen, Bronsema and Auboff, (1982) first articulate a paradigm of a 'common core' of information systems applications with 'local' alterations. There has been little further development of this model as far as the functionality of application systems is concerned, and Ives and Jarvenpaa, (1991) conclude that "the literature offers little guidance for...local versus common applications". The notion of a common structure, linking together divergent (local) elements of a global system, however, has been further developed by Keen (1991) who states that a 'transnational platform' is required to carry the 'transnational information technology capability' required for global operations.

Both Kosynski et al (1993) and Sankar et al (1993) mainly include hardware and 'middleware' elements in their interpretation of information technology architecture. However, Butler Cox (1991) include application systems in their definition of systems architecture. Also, information technology infrastructure, in the sense Weill (1992) and Weill et al (1994) define and interpret it, does include (common parts of) application systems. This is in line with Earl (1989) who argues that if the architecture in question should have relevance to the development of business systems, then all the elements which make up such business systems need to be included in it.

An architecture for international systems could therefore be postulated, which has two dimensions to it, namely the system's 'topology' and the characteristics of its 'elements'. The topology of the system is what designates the parts and defines their relation to each other'. The parts of the topology would thus consist of a 'common core' and 'local variations' of the system, linked together by a 'core/local interface'. Figure 4. illustrates such a architecture model. Using Kroenke and Hatch's (1994) practical definition of the components of an information system, these parts consist of five elements, namely people, procedures, data, software and hardware. The sum of the characteristics of each element (such as the typical technology platform, typical application programs, etc.) together shape the characteristics of the overall system.

In line with Glaser and Strauss' (1967) requirement that such a basic conceptual mode should be grounded in the researcher's experience and should be based on 'lived' anecdotal evidence, it seems appropriate to contrast this concept with some live experiences with international information systems.

5 The term 'topology' is chosen (rather than 'structure') because what is being described is likely to appear in many disguises; a structure always needs to be recognisable as such, whereas a topology, by definition, is "the [set of] properties..which remain unchanged even if [the shape] is bent, stretched, etc." (Chambers Twentieth Century Dictionary, 1972 Ed) 


\section{Generic Systems Topology}

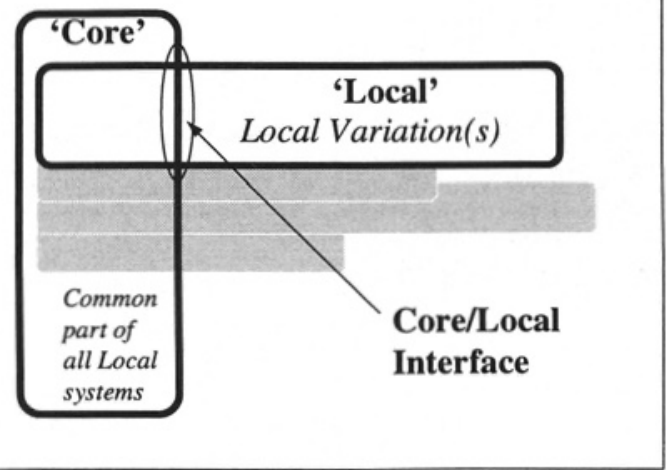

Figure 4. The conceptual 'Core/Local' topology

\section{THE ARCHITECTURE MODEL AND EMPIRICAL OBSERVATIONS}

Three case vignettes from the author's own experience are used to explore whether the architecture model postulated eo ipso is useful in the practical explanation and interpretation of the cases as well as a candidate for a 'paradigmatic' theory of the structure of international information systerns.

\subsection{The leasing subsidiary of an international bank}

The firm was acquired by an Asian international bank to give them a base in the leasing business with branches in the USA, the UK and three European countries. The central computer into which all offices were linked was in New York. It soon transpired that systems were inadequate for expansion and the hardware was obsolete. A complete re-design of their information systems technology was therefore needed.

The business in the various countries was firmly limited to instalment credit transactions and differed mainly in magnitude. This premise of business being the same did, however, not translate into systems terms. While the lease set-up process was similar, the lease administration part, which makes up more than two thirds of the system, differed significantly from country to country.

To cope with this diversity the new international system had two main components:

- A common leasing module dealt with credit and exposure management; it would set up the lease deals and the receivables stream;

- Local country modules would receive the basic data for input into the country-specific receivables and marketing modules, to cope with local languages as well as differing business practices. 


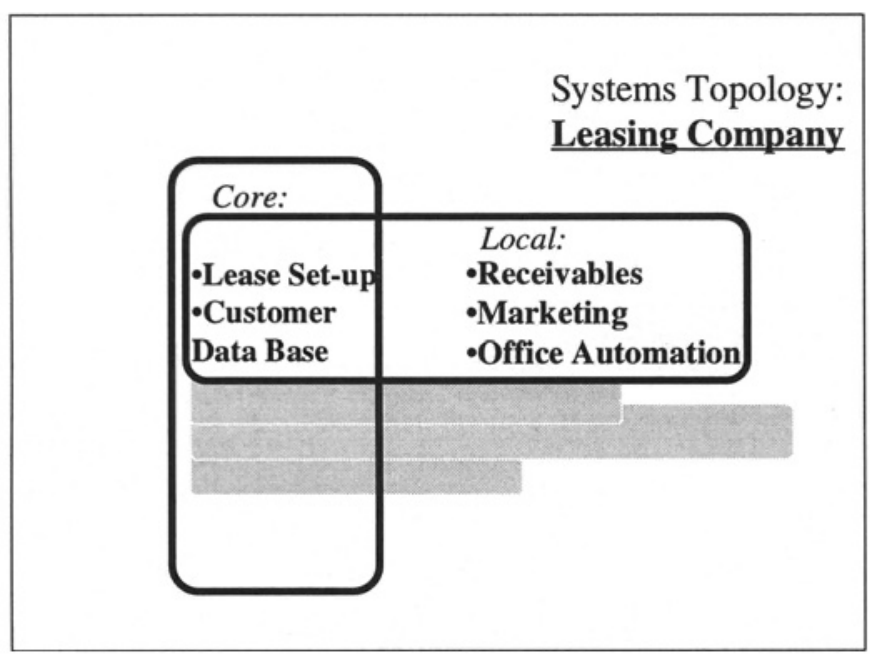

Figure 5. The balanced topology of the Leasing Company

The topology of the new systems was thus characterised by

- A 'core of central application software for those key functions which need to be globally controlled,

- Freedom for 'local' information technology applications, apart from stringent data interface standards;

- Technical people at the centre and business-oriented applications managers at the 'local' sites.

In terms of global business strategy, the leasing company balances strong global control over with wide local autonomy to use the local environment to best advantage. This classifies them as Global Coordinator/Transnational.

\subsection{An Australasian merchant bank}

This New Zealand based merchant bank with substantial branches in Australia and London had expanded rapidly. The business of the bank consists mainly of money market dealing, investment banking and stock broking. Information systems technology at the head office was fragmented and the branches ran odd assortments of software and equipment, loosely linked by public networks. A newly appointed central Treasurer set out to install systems and controls.

There were two levels of information and systems needs:

- A comprehensive management control system to monitor exposure and risk internationally as well as for each local firm;

- Operations, specifically in the money market and stock broking activities required more systems support.

The resultant international system consisted thus of a narrow 'core' which only contained detailed and stringent data interface and communication standards for input into the Treasurer's own monitoring system. As an incentive to comply with the standards, an electronic mail and bulletin board service was 
offered on the 'core'. The 'local' systems were seen as entirely composed of the best suited local software, adapting to the diverse environments for money market and stock broking operations, provided they could comply with the data and information interface requirements. The branches would rely entirely on local, external technical and applications support.

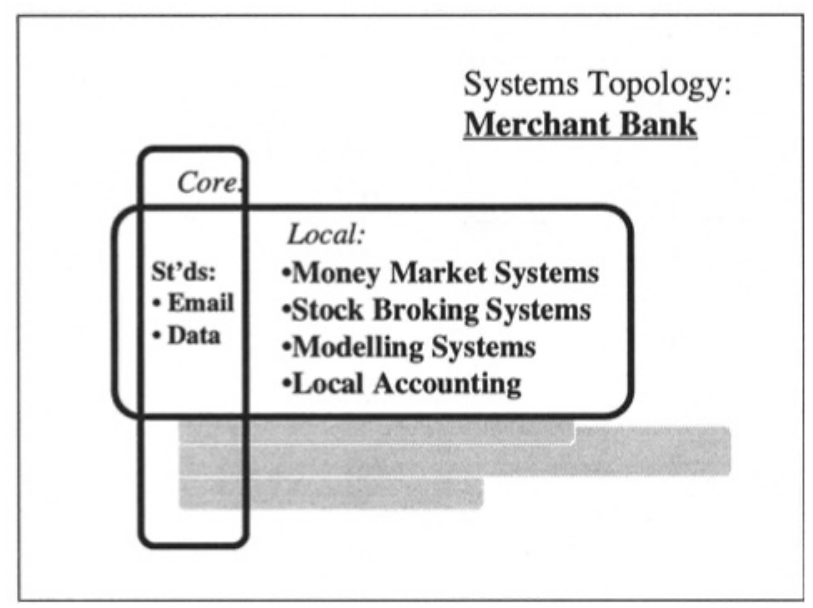

Figure 6. Dominance of local systems in the Merchant Bank's topology

The main characteristic of this system's topology is thus a thin 'core', consisting entirely of standards and recommendations. The 'locals' enjoy freedom of choice of information systems technology as long as they comply with the laid down interface standards. Only some of the system elements are well defined:

- Data and information standards for the group management information system are non-negotiable;

- Hardware standards rely on incentives;

- Operating procedures are largely locally defined and local systems are all supported by external agents;

The merchant bank gives thus high autonomy to its local offices and imposes only a reporting regime from the centre. It is low on global control and classified as a National Adaptor/Multinational;

\subsection{A New Zealand commodity exporting board}

The Board has a virtual monopoly in the purchase of fruit from producers. It owns packing houses and cool stores in New Zealand, operates its own charter fleet and runs a number of European sales offices, while North American sales are controlled through an agency. Asia is an important target for development in the near future.

The Board's systems strategy centres around strong production systems with some marketing modules integrated into them. The international part is, however, the smallest part of the system and consist mainly of common messaging formats. The shipping system is designed to send shipment details and forecasts to the branches who can send sales statistics back to the centre. Some of the overseas sales offices use sales order entry systems specific to their environment. 


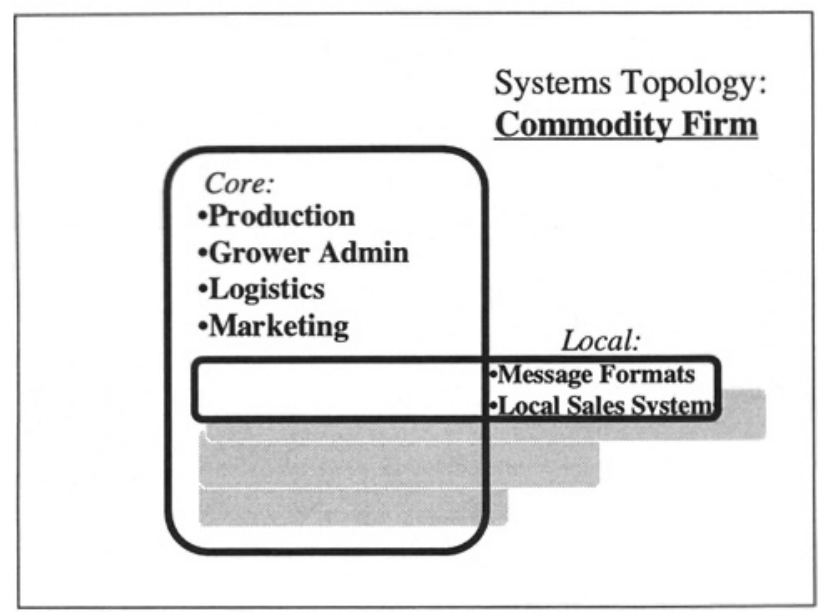

Figure 7. Systems Topology of the Commodity Firm

The architecture consists of:

- A - large - 'core' of extensive and sophisticated systems in the production, logistics and marketing (forecasting and decision-support/modelling) areas;

- The messages and the independent sales and administration support systems at the branch offices are thus the only 'local' parts in the topology of this international system.

The commodity firm is strong on global control, leaving relatively little autonomy to the local sales offices. This classifies them as Exporter/Global.

\subsection{Summary of the Case Vignettes}

Table 1 overleaf summarises the topology and systems element characteristics of the three cases.

The degree of balance between local autonomy and global control in these three cases seems to be closely correlated to the topology of international systems. This confirms the literature on the influence of strategy on information systems structure mentioned above (see 2.2). A topology of large 'local' technology, compared to thinner 'core' components seems to correlate to the higher degree of local autonomy and low level of global control as reflected in the Merchant Bank's organisational strategy. The balance in global vs. local control in the structure of the leasing company is reflected in a medium-to-large 'core' and equally sized 'local' systems. High global control and little autonomy for the branch sites in the commodity firm has lead to an architecture characterised by a large 'core' of systems at the centre and only a thin smattering of 'local' systems. 
Table 1. Summary of the case histories

\begin{tabular}{|c|c|c|c|}
\hline $\begin{array}{l}\text { Architecture } \\
\text { Elements }\end{array}$ & LEASING FIRM & MERCHANT BANK & $\begin{array}{l}\text { COMMODITY } \\
\text { BOARD }\end{array}$ \\
\hline 'Core' & $\begin{array}{l}\text { 'Medium core'; } \\
\text { Selective Customer } \\
\text { Data Base; Central } \\
\text { Leasing Application }\end{array}$ & $\begin{array}{l}\text { 'Thin core'; Data and } \\
\text { Information standards } \\
\text { and communication } \\
\text { standards; Electronic } \\
\text { mail and Bulletin } \\
\text { Boards (the } \\
\text { 'incentives') for free- } \\
\text { format communication; }\end{array}$ & $\begin{array}{l}\text { 'Large core"; Large } \\
\text { central system at the } \\
\text { production sites and } \\
\text { head office }\end{array}$ \\
\hline 'Locals' & $\begin{array}{l}\text { Local variations of the } \\
\text { Leasing Receivables } \\
\text { and Marketing } \\
\text { systems }\end{array}$ & $\begin{array}{l}\text { Locally selected } \\
\text { packaged technology; }\end{array}$ & $\begin{array}{l}\text { Message formats and } \\
\text { protocols for } \\
\text { communication to } \\
\text { smaller, independent } \\
\text { local systems; }\end{array}$ \\
\hline Hardware & $\begin{array}{l}\text { Indirect standard, } \\
\text { based on data } \\
\text { interface requirement }\end{array}$ & $\begin{array}{l}\text { Hardware and } \\
\text { technology guidelines } \\
\text { with incentives for } \\
\text { compliance; }\end{array}$ & $\begin{array}{l}\text { Different for each } \\
\text { location; }\end{array}$ \\
\hline Software & $\begin{array}{l}\text { Local software has to } \\
\text { accommodate the } \\
\text { standard data formats } \\
\text { output by the central } \\
\text { applications; }\end{array}$ & $\begin{array}{l}\text { Locally selected } \\
\text { packages; guidelines } \\
\text { for common accounting } \\
\text { modules; Electronic } \\
\text { mail and Bulletin } \\
\text { Boards (the } \\
\text { 'incentives') for free- } \\
\text { format communication; }\end{array}$ & $\begin{array}{l}\text { Customised, large } \\
\text { system at the centre; } \\
\text { at the local offices } \\
\text { discretion, some } \\
\text { customised, some } \\
\text { packaged; }\end{array}$ \\
\hline Data & $\begin{array}{l}\text { Stringent data and } \\
\text { communications } \\
\text { standards; }\end{array}$ & $\begin{array}{l}\text { Stringent data and } \\
\text { information standards; } \\
\text { detailed data } \\
\text { communication } \\
\text { standards (protocols } \\
\text { and time schedules); }\end{array}$ & $\begin{array}{l}\text { Message formats } \\
\text { mainly; }\end{array}$ \\
\hline Procedures & $\begin{array}{l}\text { Stringent procedures } \\
\text { for credit control and } \\
\text { lease deal set-up; }\end{array}$ & $\begin{array}{l}\text { Stringent reporting } \\
\text { schedules (ie. the effect } \\
\text { of the data standards); }\end{array}$ & $\begin{array}{l}\text { Reporting requirements } \\
\text { for the local offices; }\end{array}$ \\
\hline People & $\begin{array}{l}\text { Applications } \\
\text { managers and } \\
\text { external technical } \\
\text { support at the local } \\
\text { centres; Technical } \\
\text { management at the } \\
\text { centre; }\end{array}$ & $\begin{array}{l}\text { External applications } \\
\text { and technical support; } \\
\text { technician employed } \\
\text { by head office to install } \\
\text { and support } \\
\text { 'recommended' } \\
\text { technology; }\end{array}$ & $\begin{array}{l}\text { Large staff at the } \\
\text { central system; no } \\
\text { systems staff at the } \\
\text { local offices; }\end{array}$ \\
\hline
\end{tabular}




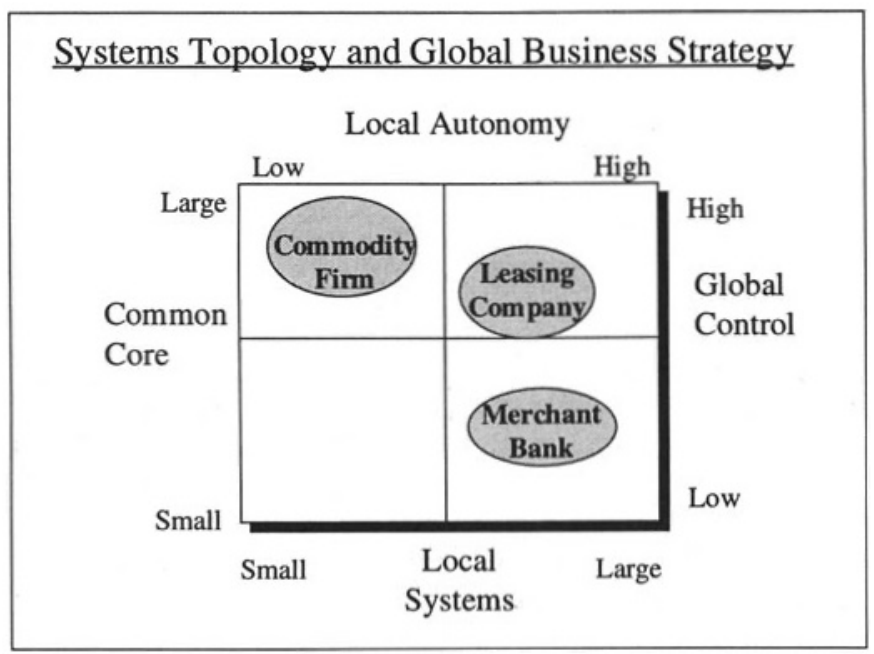

Figure 8. Link between architecture and global business strategy

Figure 8 above shows the position of the three cases with respect to their topology and global business strategy

This relationship is also indirectly confirmed by King and Sethi (1993), who in their case study also point to the "overriding role of business strategy". The optimal strategy depended to a large extent on the affinity (or otherwise) in terms of business culture and developmental level between the centre and the local sites. This flexibility to local demands and issues they identify as the key success factor for the development and implementation of an international information system.

\section{SUITABILITY OF THE ARCHITECTURE MODEL}

The model could be used with considerable ease to demonstrate and explain the nature of the systems in the cases. Furthermore it allows the demonstration of a significant property of the architecture of international information systems, ie a perceived dependency on the prevailing business strategy, in much grater clarity than the previous literature. It can thus be concluded that the architecture model is useful for practical purposes.

To ascertain whether the model is also appropriate for developing a theory from it, a set of criteria for the goodness of a theory may be applied. Mayhew (1981) and Pfeffer (1982) suggest three criteria for a good theory:

- Clarity

- Parsimony; and

- Logical coherence 
Glaser and Strauss (1967) add to this a number of criteria specific for the social sciences:

- Density

- Scope

- Integration (into a larger set of theories)

- Fit (with the data)

- Ability to work

We will now assess the model against each criteria in turn:

- Clarity; the model has only three simple terms, readily understood by any intelligent non-expert;

- Parsimony; the model can explain and implement the more elaborate architecture exemplifications contained in the literature and cited above (in italics):

* Centralised architectures have a 'local' content of (near) zero;

* Decentralised architectures have a 'core' of (near) zero;

* Integrated architectures have a varying 'core' to 'local' ratio for each element and/or for each location.

- Logical coherence; the model is derived directly from the definition of its underlying subject (ie the international information systems);

- Density; there is very little redundancy in the model:; to determine a unique manifestation of the model, each element in use would only need to be defined twofold:

* In terms of its own functionality to define the core/local split;

* In terms of its interface with its correspondent part in the core/local dimension;

- Scope; the model is defined without any restrictions in terms of application class or type; There is also no structural hurdle in the 'core/local' topology for the firm to migrate between global business strategies:

* The large 'core' of an Global firm would

* shrink as the autonomy of the parts of an Multinational increases;

* re-establishing global control for the International would increase the size of the 'core' again and decrease 'local' parts until they reach

* equilibrium in the Transnational with specific 'core/local' ratios for each business unit.

- Integration; the model seems to correlate well to the underlying business strategy; whether it also integrates well into other theoretical constructs within the - sparse - research into international information systems still needs to be investigated;

- Fit; Fitting the model to the case vignettes was possible without any 'forcing' of the data;

- Ability to work; by this is meant whether the application of the model will actually be relevant and beneficial to the problem in question, ie the difficulties with e development and implementation of international information systems. This needs more discussion.

${ }^{6}$ Bartlett \& Goshal nomenclature 


\subsection{Potential benefits of the 'core/local' architecture}

Two main areas of benefit could conceivably arise from the adoption of the proposed architecture model:

- It would provide a coherent and separate framework aimed specifically at the use and exploitation of information technology in applications of high environmental diversity (ie. international systems);

- It would point to a different, more economical and less risky way of building international systems.

Each is now discussed in turn.

\section{A framework for using information technology globally}

King and Sethi (1993) point out that "Past literature has generally ignored the international aspect of IS.." and they therefore expected that international systems developments "would fail to show any coherent strategy..".

A framework such as the two-dimensional topology, which can cater for all constellations of business strategy and the resulting systems and technology architectures, could be useful

- In the first instance as a formal, structured depository for case experience in order to build up a body of knowledge;

- Subsequently as a vehicle for developing codes of good practice for the creation and implementation of international systems; eventually this could lead to the development of a specific systems development life cycle for international systems.

\section{Impact on systems development}

Designing and developing an international system, following the two-dimensional topology architecture, would involve three systems parts:

- The 'core' of common systems (infrastructure and applications);

- The 'local' systems;

- The 'core'/local' interfaces.

These systems parts would be developed in three distinct steps:

1. First, the global business strategy would guide the definition of the 'core' parts. Deciding the nature of the infrastructure elements and delineating which functional applications are to be rigid across local sites would be the major design parameters.

2. The definition of the core parts would then allow a detailed specification of the core/local interfaces, in terms of technical standards for the infrastructure elements and in terms of data and information standards and formats for the functional and application systems parts. The technical specifications, taking into account any processing requirements and constraints as implied by the data/information interfaces, would then define a common technology platform.

3. Local' systems would be defined to complement 'core' applications requirements where these exist, or follow, within the framework of the technology platform, entirely their own specifications. 
Furthermore, the design modules can be tackled by independent teams within overlapping, or, in the case of 'local' systems acquisition projects, parallel time frames. This would spread, and thereby reduce, the development risk and would undoubtedly bring tangible time savings ${ }^{7}$.

\section{CONCLUSION AND DIRECTIONS FOR FUTURE RESEARCH}

The proposed architecture model has proved to be a practical and flexible tool to describe and understand data from a set of case vignettes. It also seems to fulfil some main criteria for a candidate for valid information systems theory. It may therefore be concluded that it may well be of use as a paradigm for future research into the structure of international information systems.

The architecture model could also have significant implications for the modus of development of international systems. Using it as a framework for the building and implementation of international information systems would allow in the first instance a systematic accumulation of a body of knowledge about this process and in the second instance enable a modular and parallel systems building approach.. This could make the development process more predictable, shorter and less risky. The two dimensional structure could also provides in-built flexibility for gradual future enhancement.

To be of practical use, however, this architecture model now needs to be validated on a much larger, diversified and altogether more representative scale. More empirical research into analysing the structure and architecture of international information systems is needed. The use of a grounded theory approach seem appropriate.

\section{REFERENCES}

Anonymous, (1991). Building a Global IT Infrastructure. I/S Analyzer, 29, 6, 1-12, 13-14.

Applegate, L.M., Mason, R.O. (1991). Information Technology and Globalization. New York.

Proceedings of the 12th International Conference on Information Systems.

Barsoux, J.-L. (1992). Following the Leaders. International Management, 47, 7, 40-41.

Bartlett, C. A. and Ghoshal, S. (1992). What is a Global Manager? Harvard Business Review, 203.

Benbasat, I., Goldstein, D.K. and Mead., 1987. The Case Research Strategy in Studies of Information systems, MIS Quarterly, September, 369-386

Bingham, J. E. and Pezzini, P. S. (1990). Systems Design for International Logistics. International Journal of Technology Management (Switzerland), 5, 4, 472-479.

Buss, M. D. J. (1982). Managing International Information Systems. Harvard Business Review, 153162.

Butler Cox plc. (1991). Globalisation: The Information Technology Challenge. Amdahl Executive Institute Research Report. London.

Cash, J.I. Jr., McFarlan, W.F. and McKenney, J.L. (1992). Corporate Information Systems - The Issues Facing Senior Executives. Homewood. Irwin.

Donovan, A., Laudan, L. and Laudan, R., 1988 Testing Theories of Scientific Change. In: Scrutinising Science - Empirical Studies of Scientific Change. Kluwer Academic Publishers, Dordrecht.

Doz, Y.L. (1980). Management in Multinational Companies. Sloan Management Review. 21, 2.

7 This development methodology is not new and is, for example, very similar to good practice in the creation of operating systems software where often a standard 'kernel' (the core) of functionality is to be applied in a number of (local) environments, some of them unknown and unpredictable at the time of writing. 
Earl, M. J. (1989). Management Strategies for Information Technology. Prentice-Hall, London.

Ehrlich, E. M. (1989). Information Technology, Global Linkage, and U.S. Competitiveness. Vital Speeches, 55, 24, 755-759.

Eisenhardt, K.M., 1989. Building Theories from Case Study Research. Academy of Management Review, 14,4, pp532-550

Galliers, R., (1993). IT Strategies: Beyond Competitive Advantage. Proceedings of the XII Conference of the South East Asia Computer Confederation, 1993, Vol.2, 105-109

Galliers, R.D. and Land, F.F., 1987. Choosing Appropriate Information Systems Research Methodologies. Communications of the ACM, 30,11,pp.900-902

Gergen, K.J. 1978. Toward Generative Theory. Journal of Personality and Social Psychology, Vol 36, p1344-1360

Glaser, B.G., and Strauss, A.L., (1967). The discovery of grounded theory. Aldine Publishing Company, Hawthorne, New York.

Goodman, S. E. and Green, J. D., (1992). Computing in the Middle East. Communications of the ACM, $35,8,21-25$.

Hamelink, C.J. (1984).Transnational data flows in the information age. Lund, Sweden: Student-litteratur $\mathrm{AB}$

Heitzman, J. (1990). Information Systems and Development in the Third World. Information Processing and Management (UK), 26, 4, 489-502.

Huff, S. L. (1991). Managing Global Information Technology. Business Quarterly, 56, 2, 71-75. Ives, B., Jarvenpaa, S.L. (1991). Applications of Global Information Technology : Key Issues for Management. MIS Quarterly.

Keen, P. G. W. (1991). Shaping the Future: Business Design Through Information Technology. Harvard Business School Press. Boston, 1991

Keen, P. G. W., Bronsema, G. S. and Auboff, S. (1982). Implementing Common Systems: One Organisation's Experience. Systems, Objectives and Solutions. 2.

King, W. R. and Sethi, V. (1993). Developing Transnational Information Systems: A Case Study. OMEGA International Journal of Management Science, 21, 1, 53-59.

King, W.R. \& Sethi, V. (1993 b) A framework for transnational systems. In Global Issues in Information Technology, Idea Publishers, Harrisburg

Kobielus, J. (1992). Privacy Issues Loom as Global Net Hurdle: Part I. Network World, 9, 3, $27-51$.

Konsynski, B. R. and Karimi, J. (1993). On the Design of Global Information Systems. Globalization, Technology and Competition. Bradley, S.P., Hausman, J.A. and Nolan, R.L. (Ed's). Boston. Harvard Business Press.

KPMG Peat Marwick. (1993). Pan-European Business Systems. London. KPMG Management Consulting Private Research Report. Brussels.

Kroenke, D. and Hatch, R. (1994). Management Information Systems. New York. McGraw-Hill.

Kuhn, T.S. , 1970. The Structure of Scientific Revolutions. University of Chicago Press, Chicago.

LaPlante, A. (1991). Global Information Officers Entering IS Picture. Computerworld, 25, 33, 70.

Lee, A., 1989. A Scientific Methodology for MIS Case Studies, MIS Quarterly, 13,1,pp32-50

Mayhew, B. H.,1981. Structuralism versus Individualism: Part II, Ideological and other Obfuscations. Social Forces. Vol 59. P627-648.

Merton, R.K., 1968. Social Theory and Social Structure. The Free Press, New York.

Neo, B. S. (1991). Information Technology and Global Competition: A Framework for Analysis. Information and Management (Netherlands), 20, 3, 151-160.

Orlikowski, W.J., 1993. CASE tools as organisational change: Investigating incremental and radical changes in systems development. MIS Quarterly, Sept 1993, p309-337 
Orlikowski, W.J., and Baroudi, J.J., 1991. Studying information technology in organisations. Information Systems Research (2:1), March 1991, p 1-28

Orlikowski, W.J.,(1995). Organisational change around Groupware. Working Paper CCS 186, Massachusetts Institute of Technology.

Palframan, D. (1991). The Great Software Sort-Out. Management Today, 86.

Passino, J. H. Jr. (1990). Harnessing the Potential of Information Technology for Support of the New Global Organization. Human Resource Management, 29, 1, 69-76.

Pfeffer, J. 1982. Organisations and Organisational Theory. Ballinger Publishing Company, Cambridge, Massachusetts.

Popper, W. J. (1990). In Pursuit of Foreign Affairs. Computerworld, 24, 19, 96.

Robey, D. and Rodriquez-Diaz, A. (1989). The Organizational and Cultural Context of Systems Implementation: Case Experience from Latin America. Information and Management (Netherlands), 17, 4, 229-239.

Sankar, C., Apte, U. and Palvia, P.(1993). Global Information Architectures: Alternatives and Tradeoffs. International Journal of Information Management, (1993), 13, 84-93.

Saraswat, S. P. and Gorgone, J. T. (1991). Multinational Issues in Information Technology: A Perspective from Less Developed Countries. Information and Management, 21, 2, 111-121.

Selye, H. 1964. From Dream to Discovery - On Being a Scientist. McGraw-Hill, New York.

Sethi, V. and Olson, J.E. (1993) An integrating framework for information technology issues in a transnational environment. In Global Issues in Information Technology, Idea Publishers, Harrisburg

Targowski, A. S. (1990). Strategies and Architecture of the Electronic Global Village. Information Society, 7, 3, 187-202.

Turner, B.A., 1983. The use of grounded theory for the qualitative analysis of organisational behaviour. Journal of Management Studies (20:3) July 1983, p333-348

Wartofsky, M.W., 1968. Conceptual Foundations of Scientific Thought. Macmillan, New York.

Weill, P. (1992). The Role and Value of information Technology Infrastructure: Some Empirical Observations. Working Paper No. 8, University of Melbourne. Melbourne, July 1992.

Weill, P., Broadbent, M. and St.Clair, D., 1994. Information technology value and the role of information technology infrastructure investments. In: Strategic Alignment, Luftman, J. (Ed), Oxford University Press, Oxford.

Wolf, A. 1922. Essentials of Scientific Method. George Allen \& Unwin Ltd, London.

Yin, R.K. 1989. Case Study Research: Design and Methods. Sage Publications, Newbury Park, Ca.

Ziman, J., 1984. An Introduction to Science Studies. Cambridge University Press, Cambridge, United Kingdom.

Zinatelli, N. and Cavaye, A., 1994: Case Study Research in Information Systems: Strategies for Success and Pitfalls to avoid. New Zealand Journal of Computing, Vol 5, Nr 1, June 1994, pp1722

\section{BIOGRAPHY}

Hans Lehmann is a management professional with some twenty five years of international experience in information technology. After a successful career in data processing management on two continents, Hans has been a management consultant with Deloittes (a large international firm of auditors and management consultants) since 1980 where he specialised in the development and implementation of international information systems for a number of blue chip companies. Austrian by birth, Hans has worked in continental Europe, the UK, Africa, North America and Australasia. In 1991 he joined the University of Auckland where his research focuses on the global application of information technology. 